\title{
Electromagnetic Interference from DC/DC Converter of Photovoltaic System
}

\author{
Zdeněk Kubík, Jiří Skála \\ Department of Applied Electronics and Telecommunications \\ Faculty of Electrical Engineering, University of West Bohemia \\ Pilsen, Czech Republic \\ zdekubik@kae.zcu.cz, skalaj@kae.zcu.cz
}

\begin{abstract}
This paper is focused on electromagnetic interference from DC/DC converter of photovoltaic system for home application. This converter produces disturbances in a wide frequency range. According to international standard CISPR 11, the frequency range for disturbance measurement could be divided to two sub-ranges $(150 \mathrm{kHz}-30 \mathrm{MHz}$ and above $30 \mathrm{MHz})$. All parts of the DC/DC converter is non-ideal and its have a parasitic parameters (especially passive components like an inductor and capacitor). These parasites often show unpredictable interference that is not easy to suppress. The simulation results of a buck converter are presented in the paper and the question about measurement correctness of the radiated emission of this device type according to the relevant standard is asked.
\end{abstract}

Keywords-EMC; photovoltaic; conducted emission; radiated emission; converter; simulation; LISN; $A M N$; CISPR 11; GCPS

\section{INTRODUCTION}

Today, a green energy is preferred before other power sources. The photovoltaic system is one of the green sources which could be installed directly in the house. There exists a lot of modification of the photovoltaic systems, like as grid connected power converters (GCPCs), off-grid systems and theirs combination. All photovoltaic systems are based on conversion of DC voltage to $\mathrm{DC}$ or $\mathrm{AC}$ voltage and some type of DC/DC converter or inverter is used. These converters produce a lot of disturbances - and it must be suppressed to the acceptable level (according to relevant standard). The limit for electromagnetic interference from photovoltaic system describes the standard CISPR 11 [1], where are also describes measurement methods for measurement of conducted and radiated emission. In the last standard version, limits for DC ports (input and output) were established. The measurement setups for conducted emission were published also in [2]. The area of electromagnetic compatibility problems producing by a photovoltaic system (generally by some type of DC/DC converters or inverters) is large, some important papers around it could be found [3] - [7].

\section{PV SYSTEM}

The home photovoltaic system describes Figure 1 - the energy from two photovoltaic panels is converted by DC/DC converters (they are driven using MPPT maximum power point tracking) and the battery pack is charged. At this time, the system drive the power by the inverter to load which is presented by AC loads or out to the mains supply. This type of system could works at a lot of modes:

- $\quad$ Off-grid mode: all home devices are supplied from the battery pack; it is directly charged by the Sun (just for sunny day and according to condition $\mathrm{P}_{\text {solar panel }}>\mathrm{P}_{\text {load }}$ ).

- Grid mode 1: a part of the power for AC home-load is taken from the battery pack, the rest of the power flows from the grid.

- Grid mode 2: all power flows to the AC home-load from grid (for cloudy days where $\mathrm{P}_{\text {solar panel }} \rightarrow 0$ ).

The battery pack can be charged from the grid for specific condition - when the battery pack is fully discharge and there is possible a reducing battery life; or in time, when the cheap energy tariff is offered.

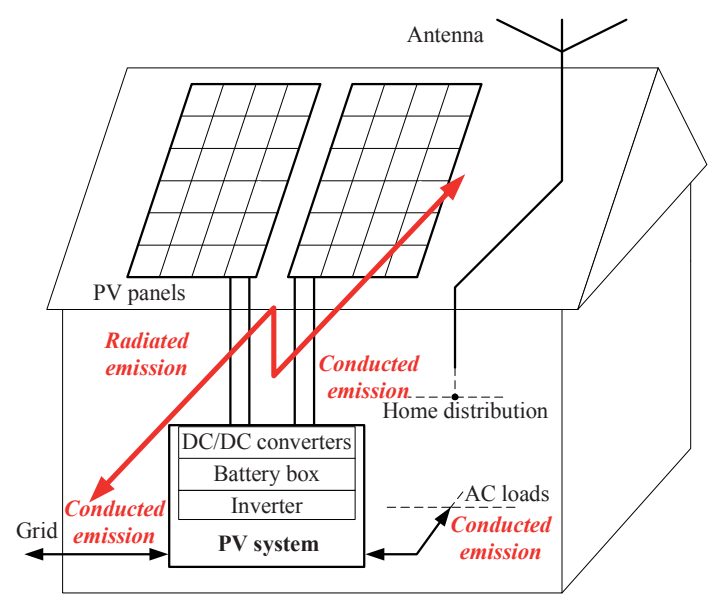

Figure 1. Block diagram of the PV system across the house

The high weight of the battery pack makes it impossible to place the system near the photovoltaic panels, but it must be placed in the basement of the building. And this solution cause issues with electromagnetic interferences.

\section{CISPR 11}

The CISPR 11 standard divides EUT to two groups and two classes [1]: 
- Group 1 equipment: group 1 contains all equipment in the scope of this standard which is not classified as group 2 equipment.

- Group 2 equipment: group 2 contains all ISM $\mathrm{RF}$ equipment in which radio-frequency energy in the frequency range $9 \mathrm{kHz}$ to 400 $\mathrm{GHz}$ is intentionally generated and used or only used, in the form of electromagnetic radiation, inductive and/or capacitive coupling, for the treatment of material or inspection/analysis purposes.

- Class A equipment is equipment suitable for use in all establishments other than domestic and those directly connected to a low voltage power supply network which supplies buildings used for domestic purposes.

- Class B equipment is equipment suitable for use in domestic establishments and in establishments directly connected to a low voltage power supply network which supplies buildings used for domestic purposes.

The photovoltaic system for home application described in this paper corresponds to the group 1 and the class B.

\section{A. Conducted emission}

The frequency range for conducted emission measurement is defined from $150 \mathrm{kHz}$ to $30 \mathrm{MHz}$. Limits for disturbance voltage on $\mathrm{AC}$ and $\mathrm{DC}$ terminals are shown in Table I. and Table II.

TABLE I. AC TERMinAl Disturbance Voltage Limits FOR CLASS B GROUP 1 EQUIPMENT MEASURED ON A TEST SITE

\begin{tabular}{|c|c|c|}
\hline \multirow{2}{*}{$\begin{array}{c}\text { Frequency } \\
\text { range }(\mathbf{M H z})\end{array}$} & \multicolumn{2}{|c|}{ Rated input power of $\leq \mathbf{2 0} \mathbf{k V A}$} \\
\cline { 2 - 3 } & $\mathbf{Q P} \mathbf{( d B} \boldsymbol{\mu V})$ & $\mathbf{A V G}(\mathbf{d B} \boldsymbol{\mu} \mathbf{V})$ \\
\hline $0.15-0.5$ & 79 & 66 \\
\hline $0.5-30$ & 73 & 60 \\
\hline
\end{tabular}

TABLE II. DC TERMINAL Disturbance Voltage Limits FOR CLASS B GROUP 1 EQUIPMENT MEASURED ON A TEST SITE

\begin{tabular}{|c|c|c|}
\hline \multirow{2}{*}{$\begin{array}{c}\text { Frequency } \\
\text { range (MHz) }\end{array}$} & \multicolumn{2}{|c|}{ Rated input power of $\leq \mathbf{2 0} \mathbf{~ k V A}$} \\
\cline { 2 - 3 } $\mathbf{Q P}(\mathbf{d B} \boldsymbol{\mu} \mathbf{V})$ & $\mathbf{A V G}(\mathbf{d B} \boldsymbol{\mu} \mathbf{V})$ \\
\hline $0.15-0.5$ & 84 to $74^{* 1)}$ & 74 to $\left.64^{* 1}\right)$ \\
\hline $0.5-30$ & 74 & 64 \\
\hline${ }^{* 1)}$ decreasing linearly with logarithm of frequency
\end{tabular}

The V-LISN must be connected to the EUT for measurement of disturbance voltage on AC terminal, see Figure 2. For DC terminal of the EUT, the DCAMN is connected between PV system and DC source $(150 \Omega \Delta \mathrm{AMN})$. Characteristic parameters of artificial networks are defined in CISPR 16-2-3 [8].

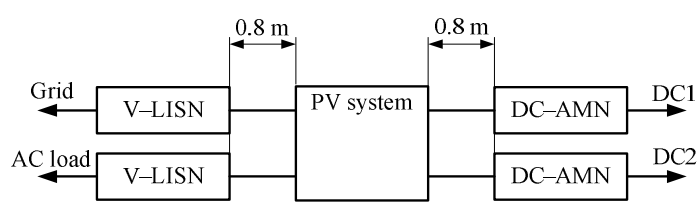

Figure 2. Block diagram for conducted emission measurement

\section{B. Radiated emission}

The frequency range for radiated emission measurement is from $30 \mathrm{MHz}$ to $1 \mathrm{GHz}$. The limits for electromagnetic radiation disturbance of small device from $3 \mathrm{~m}$ distance are shown in Table III.

TABLE III. ELECTROMAGNETIC RADIATION DISTURBANCE LIMITS FOR CLASS B GROUP 1 EQUIPMENT MEASURED ON A TEST SITE, 3 M DISTANCE

\begin{tabular}{|c|c|}
\hline \multirow{2}{*}{$\begin{array}{c}\text { Frequency } \\
\text { range }(\mathbf{M H z})\end{array}$} & Rated input power of $\leq \mathbf{2 0} \mathbf{k V A}$ \\
\cline { 2 - 2 } & $\mathbf{Q P}(\mathbf{d B} \boldsymbol{\mu} \mathbf{V} / \mathbf{m})$ \\
\hline $30-230$ & 40 \\
\hline $230-1000$ & 47 \\
\hline
\end{tabular}

The small devices must be placed in the cylindrical test area with maximum diameter $\mathrm{d} \leq(1.2 \pm 0.1) \mathrm{m}$ and height $\mathrm{h} \leq(1.5 \pm 0.1) \mathrm{m}$. Figure 3 shows the typical test area for small device. The distances between devices are $\mathrm{D} \geq 0.1 \mathrm{~m}$ and $\mathrm{B}$ equals to distance from 30 to 40 $\mathrm{cm}$ (bundle for long cables).

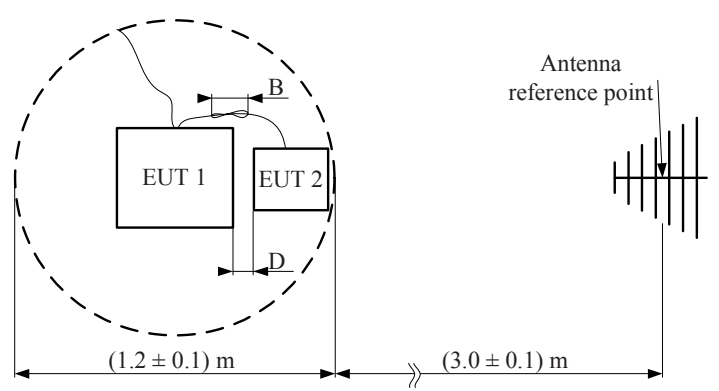

Figure 3. Test area of small device for radiated emission measurement - top view

For a large system which is not possible place it into $1.2 \mathrm{~m}$ diameter area is necessary to use $10 \mathrm{~m}$ measurement distance.

\section{ILLUSTRATIVE EXAMPLE}

The illustrative example represents disturbance voltage simulation of the buck converter. All simulations were performed in PSpice software. This type of converter could be used in the block "DC/DC converter", see Figure 1. Figure 4 shows schematic diagram of the ideal buck converter.

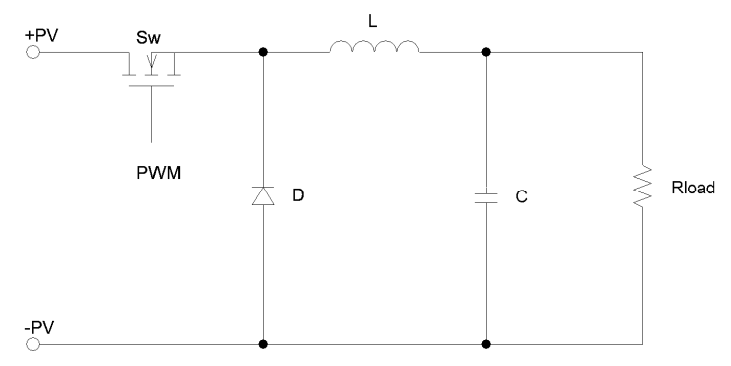

Figure 4. Schematic diagram of the ideal buck converter

Figure 5 represents schematic diagram with parasitic parameters of the inductor $\mathrm{L}(\mathrm{L}=20 \mathrm{mH}$, self-capacitance of the winding wire $\mathrm{CLp}=15 \mathrm{pF}$ and DC resistance of the wire $R L p=0.1 \Omega$ ) and the capacitor $(\mathrm{C}=100 \mu \mathrm{F}, \quad$ parasitic inductance $\mathrm{LCp}=200 \mathrm{nH}$ and equivalent series resistance $\mathrm{ESR}=0.1 \Omega$ ). 


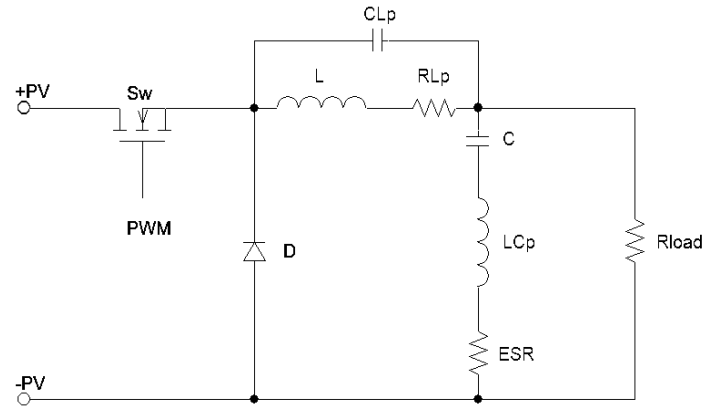

Figure 5. Schematic diagram of the buck converter with parasitic parameters of the inductor and capacitor

Simulation result of the disturbance voltage of the buck converter from Figure 5 in the frequency range $10 \mathrm{kHz}-10 \mathrm{MHz}$ is shown in Figure 6 . The switching frequency of $\mathrm{PWM}$ was set to $\mathrm{f}=100 \mathrm{kHz}$, rise and fall time $t_{r}=t_{f}=100 \mathrm{~ns}$. There is visible the switching frequency of the converter $(100 \mathrm{kHz})$ and its harmonics. These components of the disturbance voltage could be effectively reduced by conventional LC filter. The main problem of the conventional LC filter is its parasites of capacitor and inductor - the filter (designed to the frequency range from $150 \mathrm{kHz}$ to tens of $\mathrm{MHz}$ ) may exhibit a decrease in attenuation at higher frequencies.

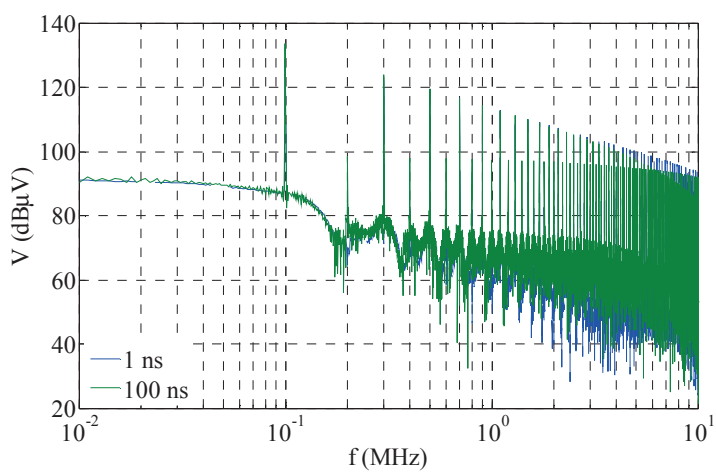

Figure 6. Simulated voltage at the output of the buck converter in the frequency range $10 \mathrm{kHz}-10 \mathrm{MHz}$

Figure 7 shows the simulation result of disturbance voltage of the buck converter in the frequency range from 30 to $100 \mathrm{MHz}$, where the start frequency represents the lowest frequency for radiated emission measurement. The most important part of the voltage is the peak at frequency approx. $85.4 \mathrm{MHz}$.

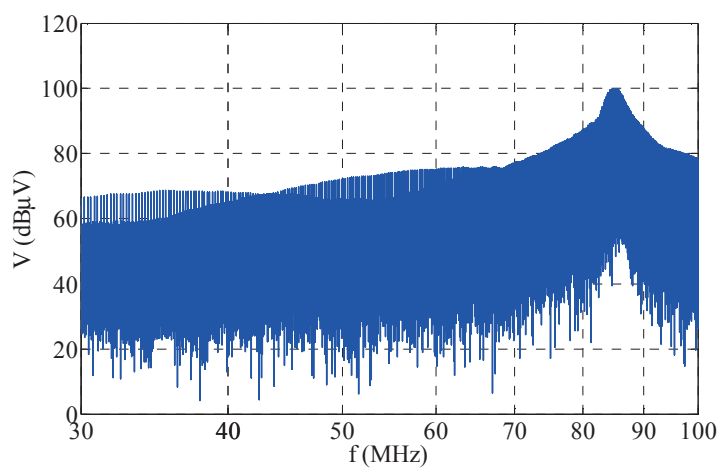

Figure 7. Simulated voltage at the output of the buck converter in the frequency range $30-100 \mathrm{MHz}$
The attenuation of the conventional LC filter at these frequencies is negligible (in most cases) and the energy could be radiated from the connected wires to the surroundings. This problem solved a special type of filter components, for example non-inductive feedthrough capacitors. Of course, shielded cables can be used - but it is not the best solution from an economic point of view.

The problem occurs at the time, where the antenna for some type of broadcasting services is placed near the photovoltaic output cable. For illustrative example, the peak at $85.4 \mathrm{MHz}$ is near to the $\mathrm{FM}$ radio band $(87.5-108 \mathrm{MHz})$. What could happen here? Some services could be disturbed or unavailable in the worst case.

According to CISPR 11, the length of the connection cables is reduced for radiated emission measurement. The question is - what happens when the length of the cables is increased? For this example, the peak frequency corresponds with the wavelength $\lambda=3.51 \mathrm{~m}$. This length is not acceptable for measurement according to the standard. And the energy is not effectively radiated from the cable. But the distance between photovoltaic panel placed on the roof and DC/DC converter which is placed in the basement of the house could be long - and the RF energy could be radiated more effectively.

The critical frequency depends on a lot of parasites of the electronic circuits - Figure 5 shows just the capacitor and inductor parasites, other parasites there are not visible (MOSFET, PCB,...).

The result of the parametric simulation, where the parasitic inductance LCp was changed, are shown in Figure 8.

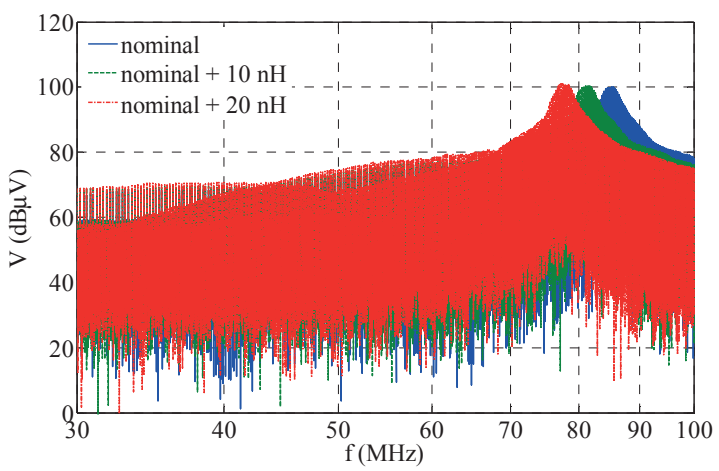

Figure 8. Simulated voltage at the output of the converter for different values of parasitic inductance LCp

The frequency of the significant peak with nominal value of LCp (around $85.4 \mathrm{MHz}$ ) is decreasing by the increasing of the inductance - the frequency peak decreases to $80.8 \mathrm{MHz}$ (for nominal value $+10 \mathrm{nH}$ ) and to $77.4 \mathrm{MHz}$ respectively (for nominal value + $20 \mathrm{nH}$ ). These changes of inductance represent longer wires of the capacitor. $1 \mathrm{~cm}$ of the capacitor wire length represents increasing of inductance approx. 10 - $20 \mathrm{nH}$. In our case, the example shows three capacitors, where the wires was extended by approx. 1 and $2 \mathrm{~cm}$ from the nominal length.

Figure 9 shows measurement result of the multilevel converter that was described in chapter II. The 
figure represents just one QP detector scan for one position of the DUT and one position of antenna (3 $\mathrm{m}$ measurement distance, log-periodic antenna, height $1 \mathrm{~m}$ above the ground plane, vertical polarization).

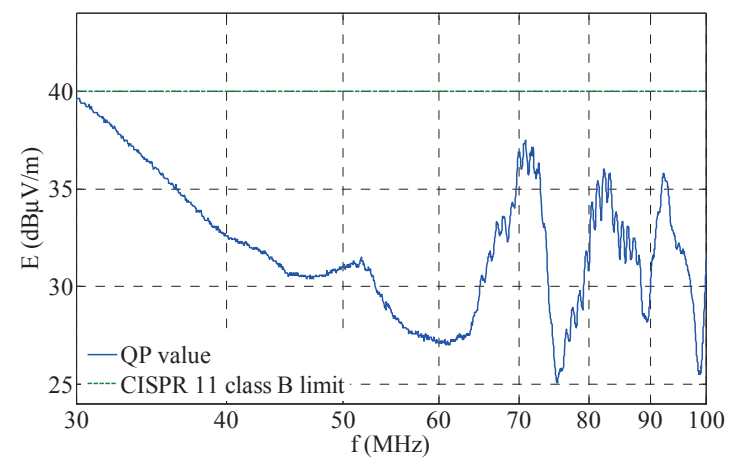

Figure 9. Measurement result of the real PV system according to CISPR 11

There are visible three dominant peaks at frequencies 70.86, 82.38 and 92.16 MHz. The last one peak interferes to the FM radio band. Cables with $1 \mathrm{~m}$ length were used for the measurement and the result shows margin less $5 \mathrm{~dB}$. The length of cables to the DC power supply (simulation of the solar panel) was changed - and amplitudes of peaks were changed too. The limit was exceeded for long cables (for length approx. $3 \mathrm{~m}$ ).

\section{CONCLUSION}

This paper describes electromagnetic interference issues of the home photovoltaic system. The disturbance limits and measurement setups for these systems are described in the standard CISPR 11 (group 1 class B device is expected). There are described limits for DC inputs and outputs (in the last version of the standard from 2015, 2016 respectively for European version of the standard EN 55011) and new type of artificial main network is used for measurement of disturbance voltage on the DC ports DC AMN, type $\Delta$ with $150 \Omega$ impedance. The frequency range (and limit for disturbance voltage on the ports) for conducted emission is from $150 \mathrm{kHz}$ to $30 \mathrm{MHz}$ and the frequency range (and limit for electromagnetic radiation disturbances) for radiated emission is from $30 \mathrm{MHz}$ to $1 \mathrm{GHz}$.

In this paper, some simulation result of DC/DC buck converter was presented. The simulation shows expected result - especially at low frequencies around switching frequency of the converter and it also shows some unpredictable behaviour of the converter - it is depends on parasitic properties of electronic parts of the converter, especially on the physical dimension of the parts or PCB. This "unpredictable" disturbance frequency interferes with FM broadcasting services and it could disturb the service (or different services on different frequencies). The simulation results were supported by measuring the prototype of photovoltaic system.

The question is - it is there necessary use short cables according to the standard for radiated emission measurement? On the other hand - it is possible measure the conducted emission for example up to $108 \mathrm{MHz}$, like at automotive? Maybe the second one is correct; there is not free space for long cables on a test site and the wavelength is almost comparable with the standard cable length for the frequency upper than $100 \mathrm{MHz}$.

\section{ACKNOWLEDGMENT}

This research has been supported by the project SGS-2018-001 and by the Ministry of Education, Youth and Sports of the Czech Republic under the RICE New Technologies and Concepts for Smart Industrial Systems, project No. LO1607 and under the project Electrical Engineering Technologies with High-Level of Embedded Intelligence, reg. number CZ.02.1.01/0.0/0.0/18 069/0009855.

\section{REFERENCES}

[1] CISPR, CISPR 11:2015, sixth edition, "Industrial, scientific and medical equipment - Radio-frequency disturbance characteristics - Limits and methods of measurement.".

[2] Y. Yoshioka, "CISPR limits for the conducted disturbances of DC ports of PV-GCPCs," 2014 International Symposium on Electromagnetic Compatibility, Tokyo, Tokyo, 2014, pp. 585588.

[3] M. Chaluvadi, G. Vincentraj and K. G. Thomas, "A Comparison Study on Conducted Emission Test in International EMC Standards," 2017 IEEE International Conference on Power, Control, Signals and Instrumentation Engineering (ICPCSI), Chennai, 2017, pp. 1352-1355.

[4] Cite:H. J. Loschi, L. A. S. Ferreira, D. A. Nascimento, P. E. R. Cardoso, S. R. M. Carvalho, and F. D. Conte, "EMC Evaluation of Off-Grid and Grid-Tied Photovoltaic Systems for the Brazilian Scenario," Journal of Clean Energy Technologies vol. 6, no. 2, pp. 125-133, 2018.

[5] H. Lu and A. K. Guru, "Modeling conducted emissions in servo drives," 2013 IEEE 8th Conference on Industrial Electronics and Applications (ICIEA), Melbourne, VIC, 2013, pp. 999-1004.

[6] H. Lu, A. K. Guru and N. Chandrasekharan, "Impact of EMI components on conducted emissions in servo drives," 2014 9th IEEE Conference on Industrial Electronics and Applications, Hangzhou, 2014, pp. 902-907.

[7] Y. Akiyama, K. Kakuda and T. Shimasaki, "Deviations of conducted disturbance voltages measured with AMN due to differences in height of the AMN and its grounding conditions," 2014 International Symposium on Electromagnetic Compatibility, Tokyo, Tokyo, 2014, pp. 501504.

[8] CISPR, CISPR 16-2-3:2016, sixth edition, "Specification for radio disturbance and immunity measuring apparatus and methods - Part 2-3: Methods of measurement of disturbances and immunity - Radiated disturbance measurements". 